\title{
Measurement of fat thickness in man : a comparison of ultrasound, Harpenden calipers and electrical conductivity
}

\author{
By R. A. D. BOOTH,* B. A. GODDARD and A. PATON \\ Physics Laboratory, Dudley Road Hospital, Birmingham 18
}

(Received 9 December 1965-Accepted 2 May 1966)

\begin{abstract}
I. Subcutaneous fat thickness has been measured by three different techniques in forty-one subjects. 2. Ultrasound provided the most accurate measurement in experienced hands. 3. A method based on electrical conductivity was also accurate but was unpleasant for the subject. 4. Harpenden calipers were the least satisfactory of the three techniques tested.
\end{abstract}

Indirect estimation of total body fat has been employed increasingly in recent years in an attempt to assess various aspects of body composition. In the most widely used method skinfold thickness is estimated by means of Harpenden calipers (Edwards, Hammond, Healey, Tanner \& Whitehouse, r955; Fletcher, 1962); these require a certain amount of practice in use. Since the instrument measures a skinfold it is likely to be inaccurate, particularly in obese subjects where a greater bulk of tissue must be deformed to obtain a reading. Errors may also arise from the varying elastic properties of both fat and skin, and the measurement itself applies a number of stresses to the fat layer. For these reasons, alternative methods would be valuable, and we have compared the results of measurements obtained by the Harpenden calipers with those given by an ultrasonic technique. We have also used a modification of a method based on the variation of electrical conductivity of different body tissues (Bauereisen $\&$ Paerisch, I953) in order to provide if possible an independent assessment of accuracy.

\section{EXPERIMENTAL}

\section{Subjects}

Measurements of fat thickness were made on a total of forty-one subjects-twentysix men and fifteen women ranging in age from 16 to 87 years. They were selected at random from the wards of the hospital, and only those with oedematous states were excluded. In some subjects, measurements were made over the abdomen approximately $5 \mathrm{~cm}$ from the umbilicus and in others about $2.5 \mathrm{~cm}$ below the inferior angle of the left scapula. All three methods were used in measurements over the abdomen, but only ultrasound and Harpenden calipers were used at the infrascapular site. Abdominal fat thickness was measured by both ultrasonic and conductivity methods in twenty subjects, and by all three methods in fourteen subjects. Infrascapular fat thickness was estimated by Harpenden calipers and ultrasonic methods in twenty-one subjects.

All observers were familiar with each of the three techniques, but in general each observer used one only, except when comparing the results obtained by two observers

\footnotetext{
* Present address: General Hospital, Birmingham 4.
} 
using a single technique. Since the direct conductivity measurement interferes with the ultrasonic measurement by breaking up the smooth fat-muscle interface, it was carried out last. The order of the other two measurements was random. Each observer's results were not disclosed until after the test had been completed in order to avoid bias.

\section{Methods}

Estimation of skinfold thickness by Harpenden calipers. This was carried out in the manner described by Fletcher (1962). A skinfold was lifted between thumb and forefinger, and the calipers were applied $\mathrm{I}-2 \mathrm{~cm}$ away and approximately in the middle of the fold. Movement of the needle often continued after application of the calipers, and the reading was taken after all movement had ceased. Either one or two observers each took three readings of skinfolds in different directions at the same site.

Estimation of fat depth by ultrasound. The equipment used initially was the KelvinHughes Mark V Flaw Detector and later the Smith 'Portex' Mark VII instrument, with polaroid camera attachment, both using 'A-scope' display. Ultrasound frequency of either $\mathrm{I} \cdot 5$ or $2.5 \mathrm{Mc} / \mathrm{sec}$ was used. The results showed no detectable difference with these two frequencies. Double probes, consisting of separate transmitting and receiving transducers, were used, having a contact surface of $3.2 \times 2.5 \mathrm{~cm}$ for the $2.5 \mathrm{Mc} / \mathrm{sec}$ probe and $3.8 \times 3.2 \mathrm{~cm}$ for the $\mathrm{I} \cdot 5 \mathrm{Mc} / \mathrm{sec}$ probe.

A block of Perspex, $5 \mathrm{~cm}$ thick, was used for calibration of the instrument before each measurement. This had previously been calibrated against water, which is equivalent to human fat (Goldman \& Hueter, 1956), giving a fat equivalent thickness of $2 \cdot 7 \mathrm{~cm}$.

A small amount of olive oil or silicone fluid was applied to the skin surface immediately before application of the probe. This provided good acoustic contact between the probe and skin surface. (Measurement of fat depth is possible because there is a small difference in acoustic impedance between fat and lean tissue, sufficient to provide an ultrasonic echo from the interface.) Careful manipulation of the orientation of the probe was necessary to obtain correct results, since the interface must be parallel to the end-face of the probe. As a general guide the probe was adjusted until the first clear echo was obtained.

Estimation of fat depth by electrical conductivity. 'Trials were initially carried out using insulated hypodermic needles (Scimitar no. r), but the best results were obtained with two stainless steel wires of diameter $0.6 \mathrm{~mm}$ passed through close-fitting plastic sleeving, allowing the wire to protrude at the tips by approximately $0.5 \mathrm{~mm}$. These were inserted into the skin, through small openings approximately $2.5 \mathrm{~cm}$ apart, made after preliminary anaesthetization with $2 \%$ procaine given subcuticularly. Electrical conductivity was obtained by measuring the current passing between the wires with a $15 \mathrm{~V}$ dry battery in series.

The procedure was as follows. One wire was inserted an arbitrary distance into the subcutaneous tissue. The other wire was advanced until the resistance showed a maximum rate of change with movement. Before withdrawal the wire was clamped with forceps to mark the position of the skin surface, and the distance between the 
forceps and the tip of the wire was then measured. The wire was inserted again to act as the arbitrary electrode, and the procedure repeated using the other wire as a probe.

In some patients the electrical resistance when the tips of the wires were within the fat layer was about $50000 \Omega$; the figure fell to $20000 \Omega$ as the tip entered the muscle layer. In the majority, however, the change in resistance at the fat-muscle interface was somewhat less than this, making detection of the interface difficult. Nevertheless, in most instances the change in resistance could be increased by introducing a small quantity of olive oil into the holes, presumably displacing interstitial fluid of comparatively high electrical conductivity.

\section{RESULTS}

The results are shown in Table r. In H.C., F.H. and J.C. the maximum opening of the Harpenden caliper was too small to accept the skinfold. When two observers are using the Harpenden calipers, the result obtained by the first tends to be higher than that obtained by the second, irrespective of observer, particularly in the more obese subjects. This may be due to gradual compression of the fat during the use of the caliper.

The ultrasonic measurements showed two depths in J.C., A.R. and L.Wa. from which similar echo intensities were obtained: these were thought to be due to an intermediate membrane layer in the fat. This layer was also detected in the conductivity measurements in subjects J.C. and G.H., where the resistance showed a sharp fall and rise as the layer was traversed by the wire tips. An intermediate ultrasonic echo of small intensity was detected in a number of other subjects. In the majority, however, a single echo was obtained, and repeated measurements showed imperceptible differences.

In H.C. the readings of fat depth from conductivity were slightly different for the two wires, presumably owing to non-uniform fat thickness; in this instance, the mean of the two readings was taken. In all other subjects the two readings were identical, but repeated measurements were not made, in order to avoid additional discomfort.

The results are illustrated graphically in Figs. $1-3$, in which regression lines are shown. It is apparent that the best correlation $(r=0.98$, standard error $= \pm 0.24)$ occurred when values obtained by the ultrasonic method were plotted against those obtained by the conductivity method (Fig. I). If Harpenden caliper readings were compared with those of the conductivity method the correlation $(r=0.8 \mathrm{I}$, standard error $= \pm 0.57$ ) was less satisfactory (Fig. 2), and this applied also to a comparison of Harpenden caliper and ultrasonic methods $(r=0.8 \mathrm{I}$, standard error $= \pm 0.60)$, both for abdominal and for infrascapular fat thickness (Fig. 3). There is a positive intercept with the latter two comparisons $(0.56 \mathrm{~cm}, P<0.01$ and $0.72 \mathrm{~cm}, P<0.001$ respectively), whereas the intercept of ultrasonic versus conductivity methods does not differ significantly from zero $(-0.06 \mathrm{~cm}, P>0.2)$. 
Table I. Measurements of subcutaneous fat thickness by three methods in forty-one human subjects

\begin{tabular}{|c|c|c|c|c|c|c|c|}
\hline \multirow[b]{2}{*}{ Subject } & \multirow[b]{2}{*}{ Sex } & \multirow[b]{2}{*}{$\begin{array}{c}\text { Age } \\
\text { (years) }\end{array}$} & \multirow[b]{2}{*}{$\begin{array}{l}\text { Weight } \\
\text { (kg) }\end{array}$} & \multicolumn{2}{|c|}{$\begin{array}{l}\text { Harpenden caliper } \\
(\mathrm{cm})\end{array}$} & \multirow[b]{2}{*}{$\begin{array}{c}\text { Electrical } \\
\text { conductivity } \\
(\mathrm{cm})\end{array}$} & \multirow[b]{2}{*}{$\begin{array}{l}\text { Ultrasound } \\
(\mathrm{cm})\end{array}$} \\
\hline & & & & $\begin{array}{c}\text { First } \\
\text { observer }\end{array}$ & $\begin{array}{l}\text { Second } \\
\text { observer }\end{array}$ & & \\
\hline \multicolumn{8}{|c|}{ Abdominal } \\
\hline L.We & $\mathbf{F}$ & 80 & $55^{\circ} \circ$ & I·79 & & 0.70 & 0.67 \\
\hline H.C. & $\mathrm{F}$ & $6 I$ & 70.0 & 一* & & $3 \cdot 04$ & $3 \cdot 30$ \\
\hline F.H. & $\mathbf{F}$ & 79 & $70 \cdot 0$ & 一* & & 3.88 & $3 \cdot 80$ \\
\hline S.R. & M & 43 & $68 \cdot 5$ & $3 \cdot 88$ & & $1 \cdot 76$ & $1 \cdot 65$ \\
\hline F.W. & $F$ & 82 & 43.0 & $3 \cdot 3^{8}$ & & $2 \cdot 00$ & I 95 \\
\hline G.T. & $\mathrm{F}$ & 66 & 70.0 & $2 \cdot 75$ & & $2 \cdot I I$ & $2 \cdot 22$ \\
\hline J.C. & $F$ & 75 & 65.0 & - * & & $3.05,2 \cdot 25 \dagger$ & $3.73,2.34 \dagger$ \\
\hline K.R. & $\mathrm{F}$ & 82 & $52 \cdot 2$ & $2 \cdot 21$ & & $I \cdot 6 I$ & $I \cdot 60$ \\
\hline G.H. & $\mathrm{F}$ & 40 & 88.0 & $2 \cdot 52$ & & $2 \cdot 16, x \cdot 61 t$ & $x \cdot 98$ \\
\hline A.R. & $F$ & 81 & 80.0 & $2 \cdot 88$ & & $I \cdot 78$ & $I \cdot 63, x \cdot 37 \dagger$ \\
\hline M.W. & $\mathbf{F}$ & 57 & $87 \cdot 2$ & $3 \cdot 58$ & & $2 \cdot 05$ & $I \cdot 63$ \\
\hline D.C. & $\mathrm{F}$ & 63 & $78 \cdot 5$ & $2 \cdot 58$ & & $2 \cdot 09$ & $I \cdot 95$ \\
\hline F.B. & $F$ & 41 & $50 \cdot 0$ & $3 \cdot 92$ & & $2 \cdot 90$ & $2 \cdot 85$ \\
\hline F.G. & $\mathbf{F}$ & 34 & $83 \cdot 1$ & $3 \cdot 69$ & & $2 \cdot 25$ & $2 \cdot 19$ \\
\hline C.Sm. & $\mathbf{M}$ & 70 & $71 \cdot 3$ & $1 \cdot 02$ & & 0.60 & 0.68 \\
\hline K.B. & $\mathbf{M}$ & 44 & $70 \cdot 5$ & 0.82 & & 0.90 & 0.72 \\
\hline J.O'H. & $\mathbf{M}$ & 55 & 90.8 & $2 \cdot 82$ & & $1 \cdot 35$ & $I \cdot 56$ \\
\hline L.Wa. & $F$ & 87 & $68 \cdot 0$ & - & & $4 \cdot 18$ & $3 \cdot 9$, I.st \\
\hline L.Wo. & $\mathrm{F}$ & 74 & 54.0 & - & & 4.00 & $\begin{array}{l}3.15 \\
4.51\end{array}$ \\
\hline A.N. & $\mathbf{M}$ & 37 & $76 \cdot 8$ & - & & I'70 & $\begin{array}{l}4.83 \\
1.88\end{array}$ \\
\hline \multicolumn{8}{|c|}{ Infrascapular } \\
\hline C.Sa. & $\mathbf{M}$ & 61 & $57 \cdot 7$ & $I \cdot 44$ & $1 \cdot 65$ & & 0.89 \\
\hline J.M. & $\mathrm{M}$ & 65 & $85 \cdot 8$ & $3 \cdot 4 I$ & 2.55 & & $3 \cdot 20$ \\
\hline C.D. & $\mathbf{M}$ & 64 & $8 \pi \cdot 3$ & $1 \cdot 27$ & $I \cdot 18$ & & $I \cdot 23$ \\
\hline A.L. & $\mathbf{M}$ & 59 & 80.4 & $1 \cdot 19$ & I. 10 & & 0.47 \\
\hline L.S. & $\mathbf{M}$ & 34 & $51 \cdot 0$ & 0.86 & $0.8 I$ & & $0.4 I$ \\
\hline W.B. & $\mathbf{M}$ & $4 I$ & $75 \cdot 4$ & $1 \cdot 32$ & $I \cdot 28$ & & 0.74 \\
\hline C.Sp. & $\mathbf{M}$ & 39 & $67 \cdot 4$ & $x \cdot 80$ & $x \cdot 73$ & & 0.74 \\
\hline A.Ha. & $\mathbf{M}$ & $5^{6}$ & $46 \cdot 4$ & $I \cdot 89$ & $x \cdot 67$ & & 0.65 \\
\hline B.V. & $\mathbf{M}$ & 54 & $85 \cdot 5$ & $3 \cdot 15$ & $2 \cdot 93$ & & 0.90 \\
\hline H.S. & $\mathbf{M}$ & 46 & $61 \cdot 3$ & $1 \cdot 13$ & $\mathrm{I} \cdot 18$ & & 0.48 \\
\hline A.Hu. & $M$ & $4^{8}$ & $72 \cdot 2$ & $I \cdot 20$ & $I \cdot \mathbf{I} I$ & & 0.47 \\
\hline M.S. & $\mathrm{M}$ & 35 & 55.9 & 0.73 & 0.73 & & 0.38 \\
\hline J.S. & $\bar{M}$ & 56 & 65.5 & 0.72 & 0.74 & & 0.34 \\
\hline A.M. & $\mathrm{M}$ & 16 & $67 \cdot 2$ & 0.74 & 0.69 & & 0.42 \\
\hline M.G. & $\mathrm{M}$ & 25 & $78 \cdot 4$ & $2 \cdot 27$ & $I \cdot 95$ & & $0.8 \mathrm{I}$ \\
\hline H.R. & $\mathbf{M}$ & 68 & $72 \cdot 2$ & 3.20 & 3.00 & & 0.97 \\
\hline E.E. & $\mathbf{M}$ & 77 & 65.4 & 0.94 & 0.93 & & 0.45 \\
\hline H.W. & $\mathrm{M}$ & 66 & $6 \mathrm{I} \cdot 8$ & 0.87 & 0.94 & & 0.45 \\
\hline A.W. & $\mathrm{M}$ & 46 & 75.0 & 0.84 & 0.88 & & 0.36 \\
\hline J.H. & $\mathrm{M}$ & 62 & $66 \cdot 9$ & I. 52 & $I \cdot 5^{I}$ & & $0.8 \mathrm{I}$ \\
\hline R.S. & $\mathbf{M}$ & 67 & $70 \cdot 4$ & I.92 & 1.82 & & $I \cdot 20$ \\
\hline
\end{tabular}

\section{DISCUSSION}

The object of this investigation was to assess the reliability of different methods of measuring fat thickness. The caliper method has certain disadvantages-the fat layer must be deformed to produce a measurable fold; the amount of fat picked up in the 
fold may vary; the elasticity of fat and skin included in the fold varies from one individual to another; and finally the caliper does not always provide a constant force over a constant area of contact throughout its range of opening. The latter defect is reduced to a minimum in the design of the Harpenden calipers (Edwards et al. 1955).

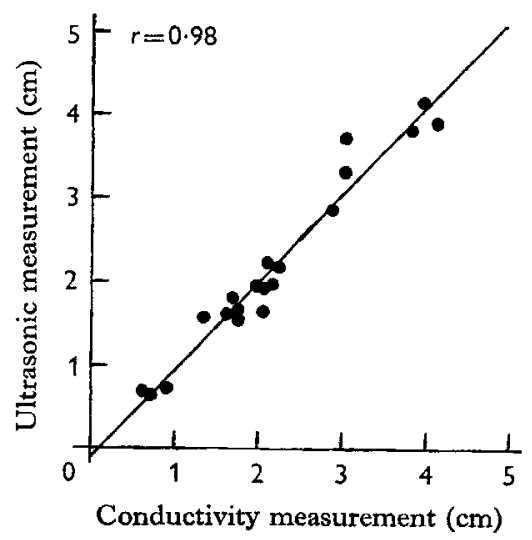

Fig. I

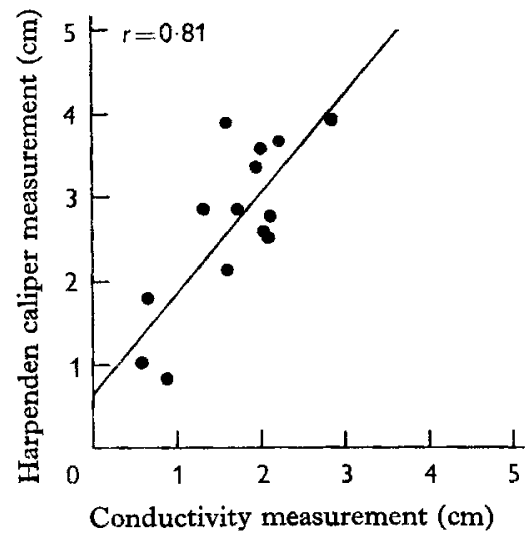

Fig. 2

Fig. r. Relationship between ultrasonic and conductivity measurements of abdominal fat thickness in twenty human subjects.

Fig. 2. Relationship between Harpenden caliper and conductivity measurements of abdominal fat thickness in fourteen human subjects.

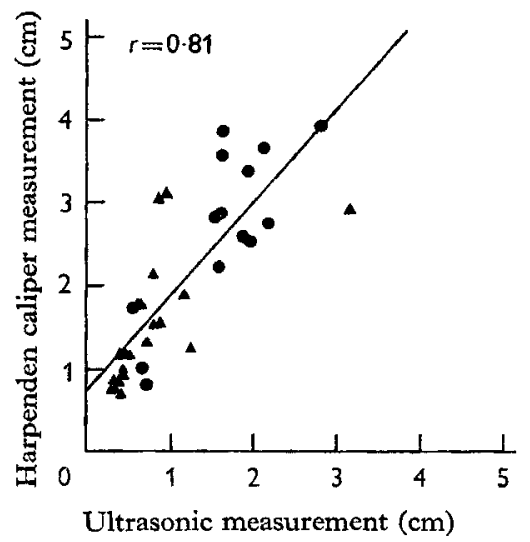

Fig. 3. Relationship between Harpenden caliper and ultrasonic measurements of abdominal ( and infrascapular ( $\mathbf{A})$ fat thickness in thirty-five human subjects.

Some information is available on the accuracy of duplicate readings with the Harpenden calipers (Edwards et al. 1955; Fletcher, 1962), but it is difficult to determine the absolute accuracy of this technique. Fletcher (I962) compared readings obtained with the Harpenden caliper in sixteen men and four women with fat thickness measured by soft-tissue radiography. He obtained an average caliper reading of $60 \%$ of the radiographic thickness of subcutaneous adipose tissue, with a correlation coefficient of $0.6 \mathrm{I}(P<0.0 \mathrm{I})$. 
A method based on electrical conductivity (Bauereisen \& Paerisch, I953) has the obvious advantage that it does not deform tissue and elastic properties are not involved. It has not been widely used, however, presumably because of the discomfort to the subject.

Ultrasonic echosounding has been employed for a number of years in agriculture for evaluating the composition of livestock. Stouffer, Wallentine, Wellington \& Diekmann ( 1961 ) compared ultrasonic measurements with carcass fat thickness and obtained correlation coefficients of $0.92(P<0.01)$ for pigs, but of only $0.32-0.54$ $(P<0.01)$ for various sites in cattle. There is of course very little subcutaneous fat in most cattle and it seems likely that man more closely resembles the pig in this respect (Fletcher, 1962). The ultrasonic technique has the advantages of the electrical conductivity method, but the equipment needed is considerably more expensive than Harpenden calipers. However, ultrasonic techniques are being employed increasingly in clinical practice, and they seemed to be worth exploring in measuring fat thickness in man.

The principal feature of the present study is the excellent correlation between ultrasonic and electrical conductivity methods. By contrast, the Harpenden caliper technique shows considerable variation compared with the other two techniques, and this increases with increasing fat thickness. Moreover it will be apparent from the graphs of the caliper readings that there is a positive intercept, indicating a probable non-linear relationship. This could be explained by an increased elastic strain produced in the larger fat folds.

Edwards et al. (1955) recommend that the figure obtained by the Harpenden caliper should be corrected by a formula which is a log transform of the observed reading. Hicks, Hope, Turnbull \& Verel (1956), on the other hand, halved the figures they obtained using an unspecified type of caliper. We have used the actual caliper reading so as to provide a direct comparison between the three methods. Moreover, if our caliper readings are plotted according to the formula of Edwards $e t$ al. the linearity of the slope is not improved. Indeed, had the relationship between caliper readings and those obtained by the other methods been linear the slope of the regression lines would be expected to be approximately 2 , if no compression of the fat fold occurred. In fact, it is nearer $\mathrm{I} \cdot 2$, a figure which agrees with the value of $60 \%$ obtained by Fletcher (1962).

The ultrasonic method is capable of greater accuracy in measuring fat thickness than the Harpenden calipers, but it should be stressed that the observer must gain experience in manipulation of the probe and in the interpretation of the echoes obtained. In the hands of the uninitiated it could prove much more unreliable than Harpenden calipers, and it cannot be recommended for occasional estimations.

Measurements of fat thickness are frequently undertaken during population surveys in the field. Where lightness of equipment and mobility are required, as in expeditions, the Harpenden calipers have obvious advantages, but under relatively static conditions the ultrasonic method offers a speedy and accurate technique over a wider range of fat thickness. 
This work was carried out during the tenure of a Research Fellowship from the Birmingham Regional Hospital Board by R. A. D. Booth. We wish to thank Dr J. A. H. Waterhouse of the Department of Medical Statistics, University of Birmingham, for statistical advice, Dr B. Pati for help with some of the Harpenden caliper measurements, and the Consultant Staff of the hospital for allowing us to study the patients. We are grateful to Miss G. Edwards for help with the manuscript.

\section{REFERENCES}

Bauereisen, E. \& Paerisch, M. (1953). Z. ges. exp. Med. 120, 389.

Edwards, D. A. W., Hammond, W. H., Healey, M. J. R., Tanner, J. M. \& Whitehouse, R. H. (1955). Br. F. Nutr. 9, $\times 33$.

Fletcher, R. F. (1962). Clin. Sci. 22, 333.

Goldman, D. E. \& Hueter, T. F. (1956). F. acoust. Soc. Am. 28, 35.

Hicks, D. A., Hope, A., Turnbull, A. L. \& Verel, D. (1956). Clin. Sci. 15, 557.

Stouffer, J. R., Wallentine, M. V., Wellington, G. H. \& Diekmann, A. (1961). J. Anim. Sci. 20, 759. 